\title{
AN INTERNATIONAL REFERENCE MATERIAL FOR RADIOCARBON DATING*
}

\section{W B MANIN}

National Bureau of Standards, Washington, DC, 20234

ABSTRACT. In August 1980, the National Bureau of Standards (NBS) issued, in the form of oxalic acid, a new International Reference Material of contemporary ${ }^{14} \mathrm{C}$ for use in radiocarbon dating laboratories. This reference material was to replace the 1975 oxalic-acid standard, supplies of which had been practically exhausted in 1978. The preparation of the new oxalic-acid standard was described in a preliminary report, as were, also, the results then available for the activity-concentration ratio of the new to the old standard obtained by a number of leading international laboratories.

With the recent completion of the analysis of all results submitted by the participating laboratories, NBS plans to issue these recently calibrated samples of oxalic acid as an NBS Standard Reference Material. There is, however, no significant difference in the reported value of its activity concentration, relative to that of the 1957 standard, from that given provisionally in 1980 .

Subsequent to our report (Cavallo and Mann, 1980) a further measurement of relative activity concentration was reported by the Radiocarbon Laboratory of Peking University. Their value, and that also for $\delta^{13} \mathrm{C}$, is insignificantly different from the average value of the results submitted by the eleven laboratories that participated in the international comparison organized by NBS.

Cavallo and Mann (1980) gave a preliminary value for a new radiocarbon-dating standard, NBS Research Material RM-49 (see also Stuiver, 1980). Since then the results have received scrutiny in various laboratories, some slight modifications and suggestions have been received, and one new result has been submitted. In spite of considerable correspondence there is some residual doubt about the statements of uncertainty by various laboratories. None had given a statement of systematic uncertainty; in fact some claimed zero such uncertainty. After many discussions it appeared to us that systematic uncertainties involving the threshold voltage of the counter plateau, pressure and temperature measurements, incomplete chemicalreaction yields, and mass-spectrometric measurements of ${ }^{13} \mathrm{C}$ abundance might amount to as much as 0.05 to $0.2 \%$. We therefore included, as a matter of prudence, an estimate of $0.1 \%$ for the

* Contribution of the National Bureau of Standards, not subject to copyright. 
systematic uncertainty in the final estimate of the overall uncertainty. After further consideration, however, the estimate of systematic error in the present paper, assessed at a level approximately equivalent to one standard deviation of the mean, has been reduced to $0.05 \%$.

In the final analysis in the preliminary certificate, however, we treated the average value from each laboratory as an independent sampling of the same population, deriving an overall average at a $99 \%$ level of confidence for the mean value of the activity concentration of the new NBS oxalic-acid standard relative to that of the old. But from the discussion at the 11 th International Radiocarbon Conference in Seattle a preference seemed to be expressed for a weighted-average value of the results to be given.

The aim of NBS in inviting participation of an international comparison of its old and new oxalic-acid standards was simply to obtain a reliable value for the ratio of the activity concentration of the new standard relative to that of the old. Three half-pound samples of oxalic acid were distributed to several laboratories -- one sample of the old oxalic-acid standard (SRM-4990) and two of the new standard. These latter comprised one sample with aliquants taken from all of 198 5-1b jars of specially prepared oxalic acid, generously provided by Pfizer Inc, and one sample taken from a single 5-1b jar randomly selected, in order to check the homogeneity of all 198 jars. The samples taken from single 5-1b jars were designated "I", and the mixed samples from all the 5-1b jars, "M" (this is described more fully in Cavallo and Mann, 1980). The measurements made by the University of Peking, Beijing, were on material from NBS Research Material RM-49 that was taken, however, from the same batch of oxalic acid as were the samples "I" and "M".

The comparison of the activity concentration of the new standard with the old standard (NBS SRM-4990) involves the measurement of activity per unit mass of each standard. The only other consideration is that in the preparation of carbon dioxide, or acetylene, from the oxalic-acid samples the yield should not be significantly different from $100 \%$, apart from random fluctuations. In the old standard this could be assessed by measuring the isotopic abundance of ${ }^{13} \mathrm{C}$ relative to ${ }^{12} \mathrm{C}$ in the gas sample. The ${ }^{13} \mathrm{C}$ abundance had been carefully measured in the old standard and is usually expressed in terms of the quantity $\delta 1{ }^{13} \mathrm{C}$, which is a measure of the difference in the ratio ${ }^{13} \mathrm{C} /{ }^{12} \mathrm{C}$ in the standard from the ratio of ${ }^{13} \mathrm{C} /{ }^{12} \mathrm{C}$ in the deposit of Belemnitella americana in the Pee Dee formation (PDB) in South Carolina.

Participants in the international measurement of the new NBS oxalic-acid standard not only measured the ratio of activity concentrations of the two standards, but also the value of $\delta^{13} \mathrm{C}$ 
for the old and new standards. The reliability of these measurements clearly depends on complete chemical yield being achieved in the conversion of the oxalic acid to carbon dioxide; as with the old oxalic-acid standard, individual values obtained for $\delta^{13} \mathrm{C}$ in future samples can be used to estimate the yield in the conversion to the counting material, and to correct for the corresponding $\delta^{14} \mathrm{C}$. In the new NBS standard it would appear, from the results shown in Table 1 , that $\delta^{13} \mathrm{C}$ is somewhat smaller in absolute magnitude -- about $17.6 \%$-than in SRM-4990. Such a decrease corresponds to an enhancement of the ${ }^{13} \mathrm{C} /{ }^{12} \mathrm{C}$ ratio, relative to $\mathrm{SRM}-4990$, in the growing of the French beet or its subsequent fermentation.

The results shown in Table 1 are also plotted as histograms in Figures $1(\mathrm{~A})$ and $1(\mathrm{~B})$. In these figures the shaded results represent values obtained in Groningen for countinggas samples (or carbon dioxide representative of the liquidscintillation-counting solution) submitted to W G Mook for massspectrometric analysis. It is very clear, from casual inspection, that neither the distribution of results for the old standard nor that for the new standard is very normal. There is indeed a very strong indication of systematic error. The average values of the two distributions, old and new, are respectively $-19.1 \% \mathrm{~g}$ and $-17.6 \%$. The difference between them is $1.5 \%$ and this, fortunately, is the only quantity used in determining the final activity-concentration ratio of the newto-old NBS standards.

Several earlier measurements have been made of $\delta^{13} \mathrm{C}$ for the old NBS standard, which is now accepted as 1ying in the range of -19.2 to $-19.3 \%$. The corresponding range of values for the new NBS standard corresponding to the difference of $1.5 \%$, would be -17.7 to $-17.8 \%$. Any values greater, in absolute magnitude, would represent possibly incomplete chemical conversion to carbon dioxide.

If, however, one takes differences in paired $\delta^{13} \mathrm{C}$ values from individual laboratories the results, shown in Figure 2 are quite remarkable. (The values of $\Delta \delta^{13} \mathrm{C}$ for laboratory 2 , shown in Table 1, were not used in plotting Figure 2.) The distribution of results, although limited in number, looks reasonably normal. The mean value and its estimated standard deviation are $(1.49 \pm 0.05) \%$. This dramatic improvement strongly suggests the existence of systematic biases in the results, shown in Figure 1, obtained by individual participants.

The weighted averages of the ratio of the activity concentrations obtained by the participants in the intercomparison are shown in Table 2. All adjustments to different values of $\delta 13 \mathrm{C}$ have been made using the factor

$$
\left(1+\delta_{1}{ }^{13} \mathrm{C} / 1000\right)^{2} /\left(1+\delta_{2}{ }^{13} \mathrm{C} / 1000\right)^{2} \text {. }
$$


TABLE 1. Reported values of $\delta^{13} \mathrm{C}$

Participating

Laboratory

1. Arizona, University of, Aust in Long

2. Bern, University of, Hans Oeschger

3. California Inst of Tech, Pasaden Sam Epstein
Susan Kurisu

4. California, Univ of, Los Angeles

Rainer Berger

W F Libby

5. California, Univ of, San Diego

T W Linick Hans Suess

6. National Physical Research Laboratory, Pretoria J C Vogel

7. Peking, University of,

Beijing

Yun $\mathrm{Si-xun}$

8. Queens University, Belfast G W Pearson

9. Rijksuniversiteit, Groningen W G Mook

10. U S Geological Survey, Denver
Irving Friedman

11. U S Geological Survey, Menlo Park $S$ W Robinson J R O'Neill

12. U S Geological Survey, Reston Meyer Rubin Tyler B Coplen

13. Washington, Univ of,

Minze Stuiver Pieter Grootes

\section{Reported Values of $\delta^{13} \mathrm{C}$} ( $\%$ oo vs PDB)

I

$-17.4$$$
\text { M }
$$

$-17.4$

$\begin{array}{ll}-17.2 \pm 0.1 & -16.4 \pm 0.1 \\ -17.12^{*} & -17.78^{*}\end{array}$

$-16.8$

$-16.8$

$-17.91$

$-18.04$

$-19.48$

$-19.3$

$-17.7$

$-17.5$

$-17.61$

$-19.28$

$-17 \cdot 14^{* *}$

$-17.52^{\star *}$

-18.52
-19.02

$-19.02$

$\left.\begin{array}{r}-17.75 \pm 0.12-17.78 \pm 0.14 \\ -17.73 \pm 0.11-17.77 \pm 0.11\end{array}\right\}$

$-17.73 \pm 0.11-17.77 \pm 0.11$
$-18.26^{*}$
$-17.81 *$

$-19.59 \pm 0.1$

$-19.53^{*}$

$-17.63$

$-17.48$

$-17.67$

$-17.65$

$-19.09$

-19.24
-19.35

$-17.50 \pm 0.02-17.52 \pm 0.02-18.75 \pm 0.02$

$-18.00$

$-18.45^{*}$

$-18.11$

$-18.36^{*}$

$-19.47 \pm 0.48$

$\Delta \delta^{13} \mathrm{C}$ between old and new standards $\%$ vs PDB)

4990
1.3
$\frac{0.6}{2.57^{*}}$
1.4
1.51

1.7

.71

1.44

1.83

$1.50^{*}$

1.54

1.58

1.24

$-17.95$

$-$

$-19.12$

1.17

$\begin{array}{ll}-17.49 & -17.48 \\ -17.84^{*} & -17.79^{\star}\end{array}$

$\begin{array}{lll}-19.00 \pm 0.04 & 1.52 \\ -19.26 \pm 0.01^{*} & 1.45^{*}\end{array}$

* Results of measurements by Professor W G Mook on șamples of counting gas or carbon dioxide, in case of liquid-scintillation counting, sent to for isotopic-abundance measurements.

** Measurements carried out using NBS Research Material, RM-49, which was distributed from same new batch of oxalic acid. 
TABLE 2. Activity-concentration ratios of new-to-o1d NBS radiocarbon-dating standards

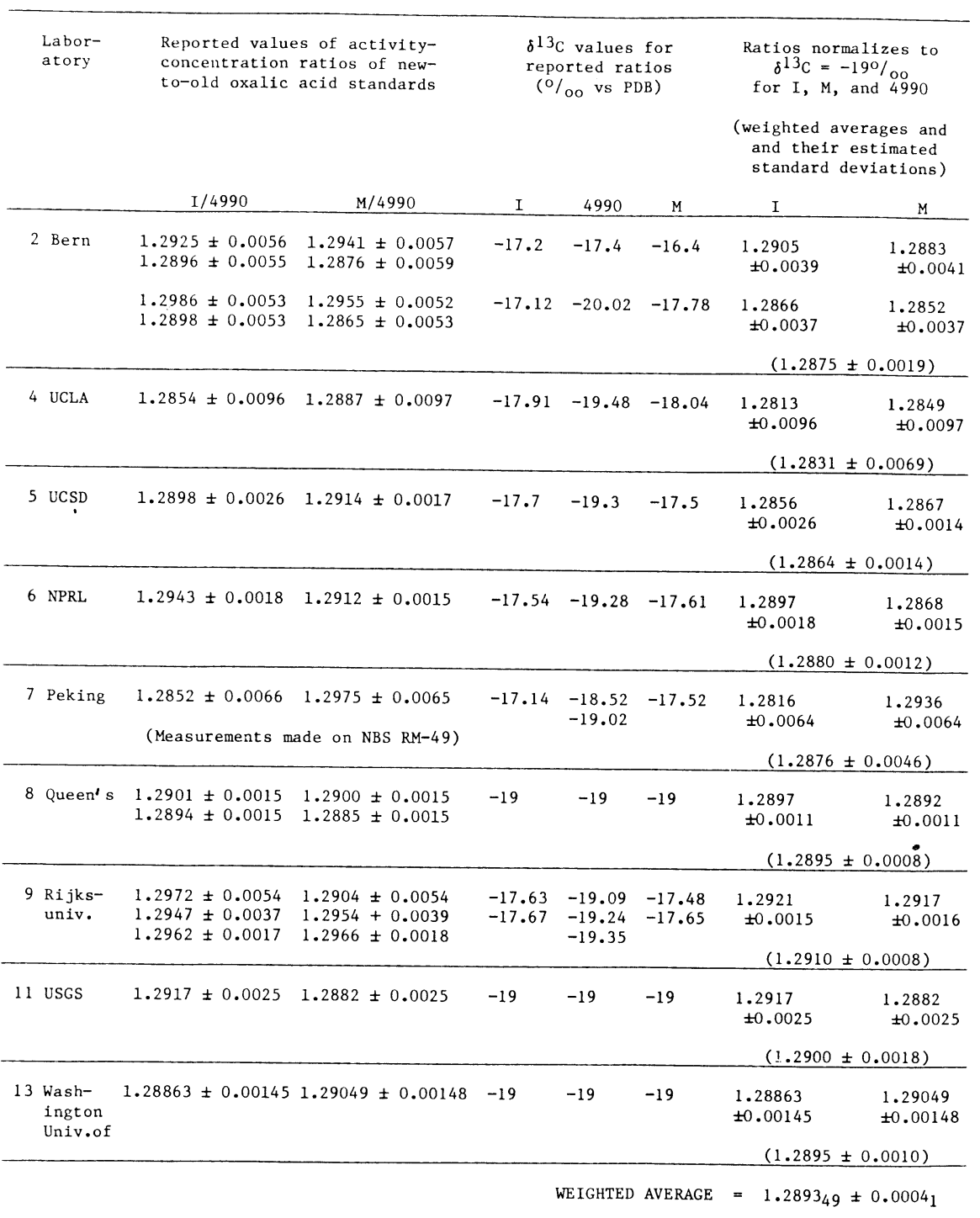




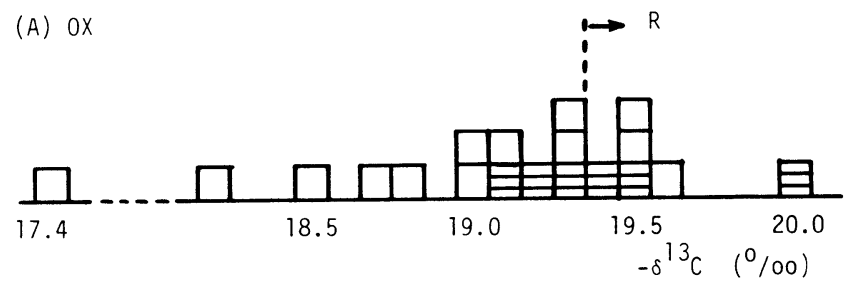

(B) NOX

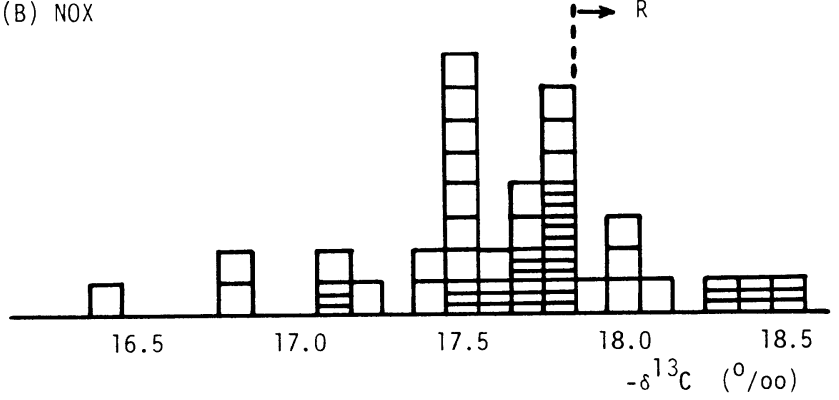

Fig 1. Histograms for values of $-\delta^{13} \mathrm{C}$ for (A) NBS SRM 4990 (OX) and (B) for NBS RM-49 -- "I" and "M" (NOX). $R$ in each of (A) and (B) represents values of $-\delta^{13} \mathrm{C}$ beyond which the data may possibly indicate incomplete chemical conversion. Shaded data points represent results obtained in the laboratory of Professor W G Mook. The average value of ox is $-19.1 \% \circ$, and its estimated standard deviation is $0.1 \%$. For NOX, the corresponding values are -17.6 and $0.1 \%$.

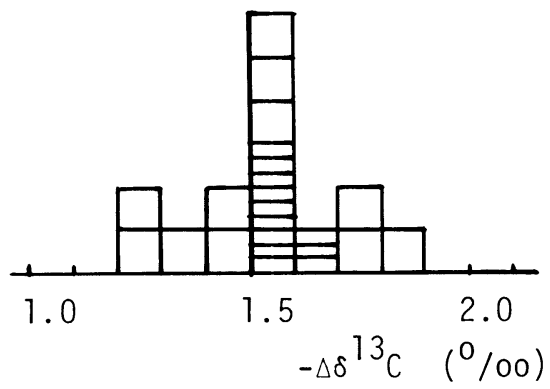

Fig 2. Histograms for values of the differences between $-\delta^{13} \mathrm{C}$ for the old and new NBS radiocarbon-dating standards. The average value of $-\Delta \delta 13 \mathrm{C}$ is $1.49 \%$ and its estimated standard deviation is $0.05 \%$ 。 
It is clear that there is no statistically significant difference between the ratios measured with samples "I" and "M". The question also arises as to the best method of treating these data; whether by taking a weighted average, or an unweighted average, the latter treating the results as a small sampling, all of equal weight, of a population. Any difference between methods of averaging might similarly give some inkling as to whether the estimate of systematic uncertainty may have been realistic or not.

The unweighted average gives ratios of the activity concentration of the new-to-old NBS standards, both normalized to $\delta^{13} \mathrm{C}$ equal to $-19.00 \%$, of

$$
1.2881 \pm 0.0008
$$

where the stated uncertainty is the estimated standard deviation of the average value.

The weighted average of the ratio and its estimated standard deviation, also normalized to a value of $\delta 13 \mathrm{C}$ equal to - $19.00 \%$, with each laboratory's submitted value weighted by the inverse of the estimated variance of that value, is

$$
1.2893 \pm 0.0004 \text {. }
$$

The difference between the weighted and unweighted averages is $0.10 \%$, and the final results from each laboratory seem to represent an excellent set of data.

As, however, I still had some reservations as to the homogeneity of the results, I consulted, as has been my wont in such situations during the last two decades, my friend and colleague Dr $\mathrm{H} \mathrm{H} \mathrm{Ku}$. Fortunately he was able to direct me to some recent work by two other colleagues, R C Paule and J Mandel (1982), that dealt with the statistical analysis of data pertaining to the measurement of the same physical quantity by different groups of experimenters, that took into account intergroup differences. Very briefly this method calculates the weighted average, $\underline{Y}$, or the $\underline{Y}_{i}$ quantities submitted by m different laboratories, name1y $\underline{Y} 1, \quad \underline{Y}_{2}, \ldots \underline{Y}_{1} \ldots$. The best estimate of the concensus value is then given by

$$
\underline{\underline{Y}}=\frac{\sum_{i=1}^{m} \omega_{i} \overline{\underline{Y}}_{i}}{\sum_{i=1}^{m} \omega_{i}},
$$

where $\omega_{i}$ is the reciprocal variance of $\bar{Y}_{i}$, as defined below. Paule and Mandel then consider the two components of uncertainty, namely the within-laboratory variance for each laboratory, 
and the between-laboratory component, given respectively by $\underline{s}_{-}^{2}$ and $\underline{s}_{b}^{2}$, to estimate $\omega_{i}$ as

$$
\omega_{i}=\left(\underline{s}_{w_{i}}^{2}+\underline{s}_{b}^{2}\right)^{-1} .
$$

The values of $\omega_{i}$ and $s_{b}$ are obtained by an iterative process, and $\omega_{i}$ is substituted in equation (1). $\left(\mathrm{s}_{-\mathrm{w}_{i}}^{2} / \mathrm{n}_{i}\right.$ in Paule and Mandel's paper corresponds to $\underline{s}_{W_{i}}^{2}$ above.)

Dr. Paule and Dr. Mandel applied their method to the set of data shown in the last column of Table 2, for all samples normalized to $\delta^{13} \mathrm{C}$ equal to $-19.00 \%$, and obtained a weighted average for the ratio of activity concentrations equal to $1.2891_{3} \pm 0.005_{3}$ (the uncertainty being the estimated standard deviation of the weighted average) and the value of $\mathrm{sb}$ of $0.0008_{1}$. They concluded that these values indicated an extrem1y homogeneous set of data.

The ratio of activity concentration of the new-to-old NBS radiocarbon-dating standards is not given by the weighted average of the results shown in the last column of Table 2 . This value, $1.2893 \pm 0.0004$, must be normalized to reflect the actual ${ }^{1 / 4} \mathrm{C}$ isotopic abundances in the two standards, and the normalization is derived from the measured difference in abundance of $13 \mathrm{C}$ between them. The normalization used is in the form of

$$
\left(1+\delta_{\mathrm{n}}{ }^{13} \mathrm{C} / 1000\right)^{2} /\left(1+\delta_{\mathrm{O}}{ }^{13} \mathrm{C} / 1000\right)^{2} \text {. }
$$

As was seen from the data shown in Figures 1 and 2 , the difference in $\delta^{13} \mathrm{C}$ is known more precisely than the actual values of $\delta^{13} \mathrm{C}$ for each standard. The normalization can therefore be calculated in the form

$$
\frac{(1-(19.30-1.49) / 1000)^{2}}{(1-19.30 / 1000)^{2}},
$$

which is quite insensitive to the value of $\delta^{13} \mathrm{C}$ of the old standard, and whether it is taken as -19.0 or $-19.3 \%$ makes no significant difference. In either case the normalization factor is 1.00304 , which gives a value for the ratio of activity concentrations of new-to-old standards of $1.29327 \pm 0.00041$. Allowing for a systematic uncertainty of 0.0006 ( $\mathrm{e}, 0.05 \%$ ) gives a final result of

$$
1.2933 \pm 0.0010
$$

The weighted average and its estimated standard deviation normalized by the factor 1.00304 , are $1.2920 \pm 0.0008$. Within the stated estimates of uncertainty the two values are certainly not discordant. 
At the 10th International Radiocarbon Dating Conference held in Bern and Heidelberg in 1979 it was agreed, for reasons to which I am not privy, that the new standard should be normalized to a value corresponding to $\delta^{13} \mathrm{C}$ equal to $-25 \%$, normalization of the old NBS standard having, by agreement, always been made to ${ }^{13} \mathrm{C}$ equal to $-19 \%$. For these two values of $\delta^{13} \mathrm{C}$ the ratio of new-to-old NBS standards would be

$$
1.2736 \pm 0.0004
$$

where the uncertainty is the estimated standard deviation of the weighted average.

\section{ACKNOWLEDGMENTS}

I wish to thank all the participants in this intercomparison for their generous help, advice, and cooperation. W G Mook kindly made and sent me an analysis of the data deriving the weighted averages of the ratio of the two standards for $\delta^{13} \mathrm{C}$ respectively $-19 \% \circ$ (old) and $-25 \% \circ \circ$ (new) which provided a most valuable check, to within $0.001 \%$, of my own calculations made by the $-19,-19 \%$ route described above. I especially acknowledge the active collaboration of Lucy Cavallo who helped with the organization of this venture until her retirement in August 1980, and both she and I are grateful to Lloyd Currie, Meyer Rubin, and Minze Stuiver who gave us substantial advice in the field that was relatively new to us. I also wish to thank J Mandel, R C Paule, and M P Unterweger for a helpful discussion on the assessment of uncertainty in intercomparisons between any number of equally competent laboratories, and also B M Coursey and D D Hoppes for reading this paper and for help in the details of preparing the standard and its certificate for distribution. And last, but by no means least, we at NBS and the members of the international radiocarbon-dating community wish gratefully to acknowledge the help and cooperation of $G$ D Lauback, $H$ F Hammer, A J Schatz, and A J Schmitz of Pfizer Inc, for not only providing the oxalic acid for this new standard but for assuring the quality and homogeneity of the final product.

\section{REFERENCES}

Cavallo, L M and Mann, W B, 1980, New National Bureau of Standards contemporary carbon-14 standards, in Stuiver, M and Kra, R S, eds, Internat $1{ }^{14} \mathrm{C}$ conf, 10th, Proc: Radiocarbon, $\mathrm{V} 22$, no. 3, p 962-963.

Paule, R C and Mandel, J,1982, Consensus values and weighting factors: NBS Jour Research, v 87, p 377-385.

Stuiver, M, 1980, Workshop on $14 \mathrm{C}$ reporting, in Stuiver, $\mathrm{M}$ and Kra, R S, eds, Internat $1{ }^{14} \mathrm{C}$ conf, $10 \mathrm{th}$, Proc: Radiocarbon, v 22, no. 3, p 964-966. 